\title{
Square Microstrip Antenna with Dual Probe for Dual Polarization in ISM Band
}

\author{
Priyanka Yadav ${ }^{1}$, Abhilasha Mishra ${ }^{2}$ \\ ${ }^{1}$ E\&TC Dept., MIT, Aurangabad (India). \\ ${ }^{2} E \& T C$ Dept., MIT, Aurangabad (India).
}

\begin{abstract}
This paper presents the design of antenna operating in ISM band at $2.4 \mathrm{GHz}$. The designed square patch antenna is dual polarized with two rectangle shaped slot inserted on the patch. The FR4 dielectric material is used for the antenna consist of Dual probe feed with ground plane. HFSS software is used for the simulation which shows the result for isolation as $28 \mathrm{~dB}$, antenna gain of $5.96 \mathrm{~dB}$ and bandwidth $222 \mathrm{MHz}$.
\end{abstract}

Keywords: Dual feed, Dual polarization, ISM Band, Probe Feed, Square MSA

\section{INTRODUCTION}

Due to well known characteristic Microstrip Antenna have been used successfully in many application. Innovative configurations with very flexible performances have been finding increase in use in new telecommunication services mainly in the wireless market [1]. According to standard of IEEE for WLAN the networks works at the frequency of $2.4 \mathrm{GHz}$. Usually, the wireless communication systems are often faced with many problems of multiple path fading. Recently, research work has focused on frequency reuse and polarization diversity involving the use of two orthogonal polarizations [2]. This allows communication systems to be able to send and receive signal with more alternative polarization. The polarization diversity antenna is composed of two monopole antenna radiating with different orthogonal polarizations operating at same frequency [3]. In this paper design of linearly polarized square patch with dual feed is proposed [4]. Dual Feed excites two orthogonal field components with equal amplitudes but a $90^{\circ}$ phase difference.

\section{ANTENNA STRUCTURE}

Microstrip patch antenna consists of a radiating patch on one side of a FR4 which has a air gap, ground plane on the other side as shown in fig. 1. The patch is square shaped made up of conducting material copper. The radiating patch having two rectangles. Glass epoxy (FR4) of dielectric constant of 4.4 and loss tangent of 0.002 is used as dielectric material.

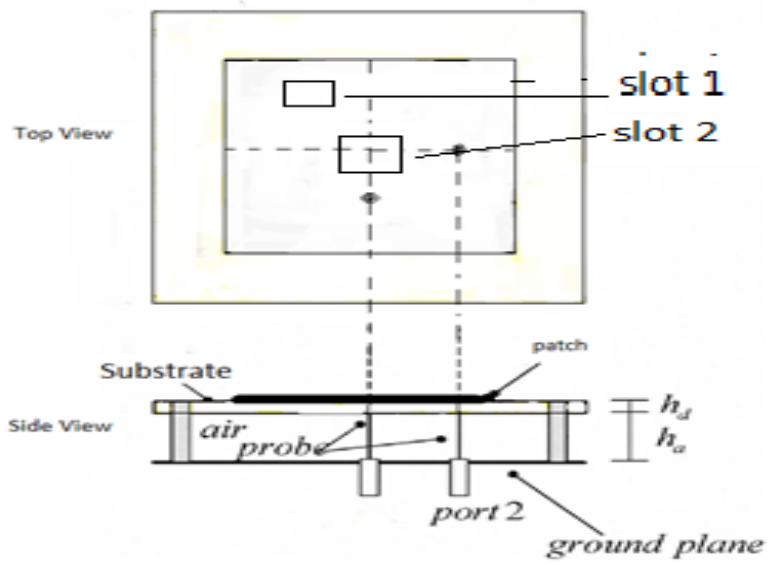

Figure 1: Antenna Structure

\section{ANTENNA DESIGN AND RESUlTS}

Antenna is designed to operate at $2.4 \mathrm{GHz}$ which is an ISM band. The radiating patch is square shaped so; it's having same length and width. Square patch antenna is designed using following equation [5]:

Width of patch:

$$
w=\frac{c_{0}}{2 f_{r} \sqrt{\epsilon_{\text {eff }}}}-\frac{2\left(h_{d}+h_{a}\right)}{\sqrt{\epsilon_{a v}}}
$$

Effective Dielectric constant: 


$$
\epsilon_{\text {eff }}=\frac{\epsilon_{a v}+1}{2}+\frac{\epsilon_{a v^{-1}}}{2 \sqrt{1+\frac{10\left(h_{d}+h_{a}\right)}{w}}}
$$

Fig. 2 shows the simulated return loss and isolation of the antenna versus the frequencies in the $1.8-3$ $\mathrm{GHz}$ frequency range for the probe distances $\mathrm{D}$. The isolation has a maximum value of $28 \mathrm{~dB}$ at the frequency of $2.25 \mathrm{GHz}$ with return loss of $22 \mathrm{~dB}$ at resonant frequency of $2.44 \mathrm{GHz}$. The air gap provides a222 $\mathrm{MHz}$ bandwidth, at $10 \mathrm{~dB}$ return loss.

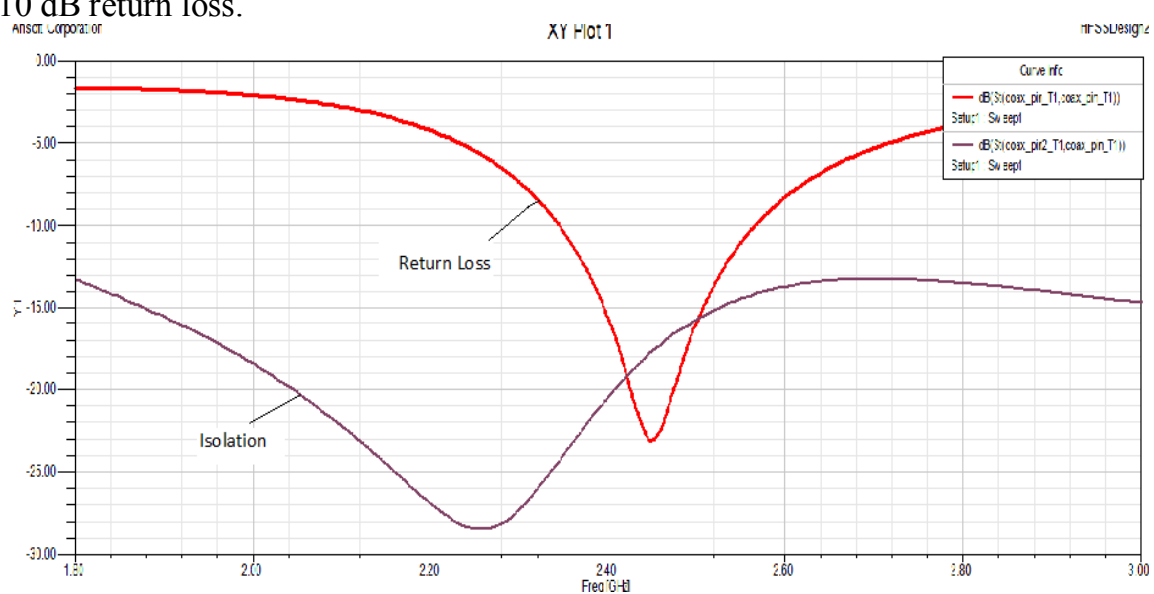

Figure 1: Return loss and Isolations of the antenna

Fig. 3 shows the VSWR of antenna which is 1.33

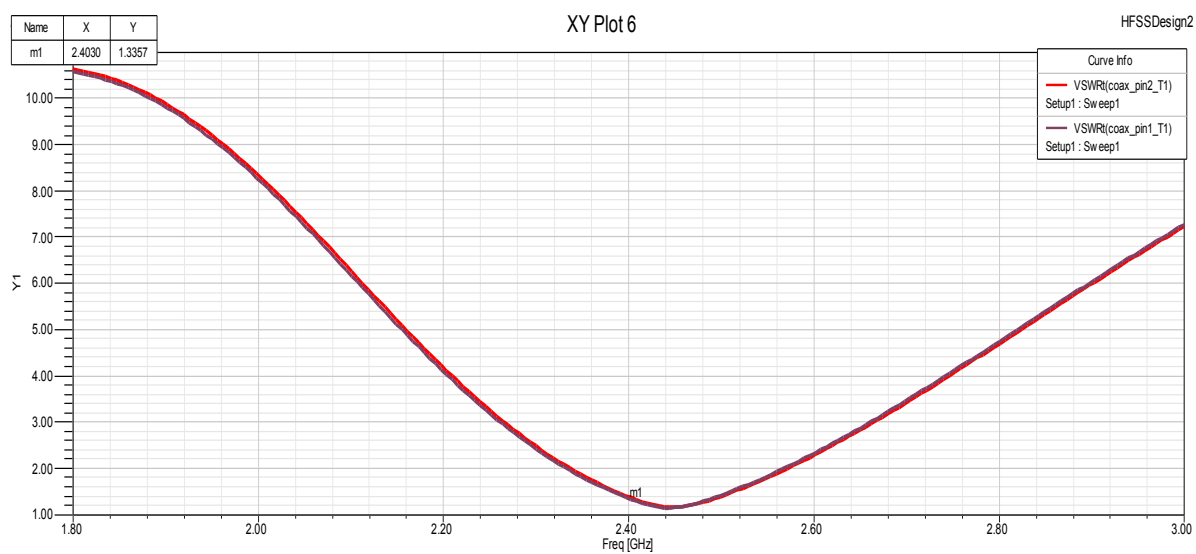

Figure 3: VSWR

Fig. 4,5 shows the radiation pattern of $\mathrm{E}$ and $\mathrm{H}$ plane respectively, with $5.96 \mathrm{~dB}$ gain.

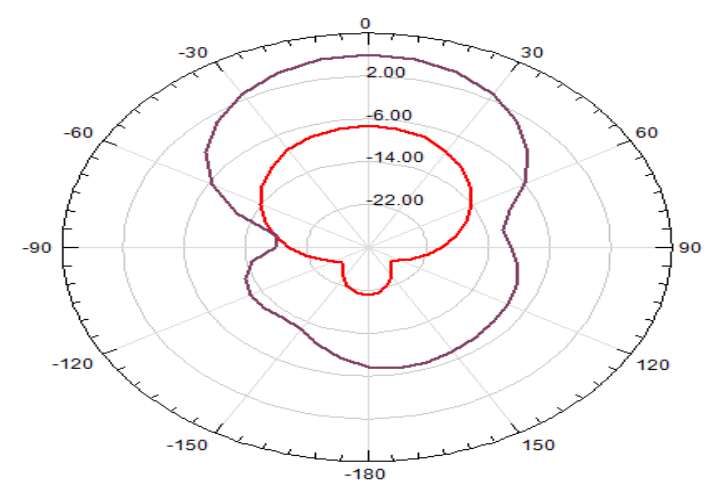

Figure 4: Radiation pattern excitation at $2.4 \mathrm{GHz}$ E plane 


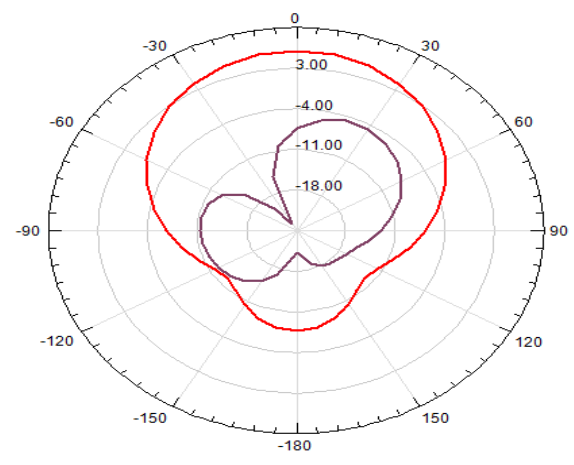

Figure 5: Radiation pattern excitation at $2.4 \mathrm{GHz} \mathrm{H}$ plane

\section{CONCLUSION}

A dual-polarized microstrip antenna with high isolation is simulated. The high isolation is achieved by inserting rectangular slots into the radiating patch. Simulated results show that the antenna has $28 \mathrm{~dB}$ isolation with the moderate antenna gain of $5.96 \mathrm{~dB}$.

\section{References}

[1]. Teresa Condella, Custodia peixeiro "Dual band dual polarisation slotted microstrip patch antenna element" IEEE 2001

[2]. Wong, H., Lau, K.L., and Luk, K.M., "Design of dual-polarised L-probe patch antenna array with high isolation", IEEE Trans. Antennas Propag.,52, (I), pp. 45-52, 2004

[3]. K. Boonying, T. Laohapensaeng, S. Kosulvit and C. Phongcharoenpanich," A Flat Antenna for Polarization Diversity", JICTEE-2010, Luangprabang Lao PDR, December 2I-24,pp.528-530.

[4]. Teeravisit Laohapensaeng, Komkris Boonying, "Dual-Polarized microstrip antenna with high isolation using an inserted slot", 2011 International Symposium on Intelligent Signal Processing and Communication Systems (ISPACS) December 7-9, 2011

[5]. Girish Kumar and K. P. Ray, "Broadband Microstrip Antennas", Artech House, 2003, pp. 29 - 60 